Revue

Revue de l'histoire des religions

de Ihistoire

des religions

$3 \mid 2020$

Varia

\title{
Le Christ à Port-Royal, textes réunis par Laurence DEVILlAIRS et Laurence PLAZENET
}

Paris, Société des Amis de Port-Royal («Chroniques de Port-Royal », 67), 2017

Dan Arbib

\section{OpenEdition}

Journals

Édition électronique

URL : https://journals.openedition.org/rhr/10741

DOI : $10.4000 /$ rhr. 10741

ISSN : 2105-2573

Éditeur

Armand Colin

Édition imprimée

Date de publication : 1 septembre 2020

Pagination : 481-484

ISBN : 978-2-200-93327-2

ISSN : 0035-1423

Référence électronique

Dan Arbib, «Le Christ à Port-Royal, textes réunis par Laurence Devillairs et Laurence Plazenet », Revue de l'histoire des religions [En ligne], 3 | 2020, mis en ligne le 01 janvier 2021, consulté le 05 janvier 2023. URL : http://journals.openedition.org/rhr/10741 ; DOI : https://doi.org/10.4000/rhr.10741

Ce document a été généré automatiquement le 5 janvier 2023.

Tous droits réservés 


\section{Le Christ à Port-Royal, textes réunis par Laurence DEVILLAIRS et Laurence PLAZENET}

Paris, Société des Amis de Port-Royal («Chroniques de Port-Royal », 67), 2017

Dan Arbib

\section{RÉFÉRENCE}

Le Christ à Port-Royal, textes réunis par Laurence DeVILLAIRS et Laurence PlAzENET, Paris, Société des Amis de Port-Royal (« Chroniques de Port-Royal », 67), 2017, 24 cm, 393 p., $38 €$, ISBN 979-10-92360-04-2.

1 Il s'agit là des Actes du colloque international de la Société des Amis de Port-Royal tenu à l'université Paris-Sorbonne et au Musée national de Port-Royal des Champs les 6 et 7 octobre 2016. Au point de départ, le constat que la christologie est le parent pauvre de la théologie du XVII ${ }^{\mathrm{e}} \mathrm{s}$. - à l'exception de Port-Royal précisément. C'est cette exception que ce collectif entend mesurer. Après une introduction enlevée et très fénelonienne de L. Devillairs, pour qui le passage du christocentrisme à un théocentrisme de réception donne lieu au "passage de la christologie à l'anthropologie " (jusqu'à Kant) et à une «substitution de la christologie à la théodicée » (chez Fénelon par exemple) (p. 20-21), l'ensemble se divise en quatre parties.

Une première partie examine les enjeux de l'incarnation et de l'imitation « Vie et mort $\mathrm{du}$ Christ: incarnation et imitation ». Alors que D. Donetzkoff orchestre le concept d'imitation du Christ chez Saint-Cyran («Vivo ego, jam non ego, vivit vero in me Christus : Saint-Cyran et l'imitation du Christ», p. 27-43) pour qui il s'agit toujours de « restaur[er] l'image divine en l'homme » (p. 34), que T. M. Harrington prétend éclairer les "Miracles christiques dans L'abrégé de la vie de Jésus " au moyen d'une méthode numérologique qu'on peinerait à qualifier (pythagoricienne, cabalistique, 
Davincicodienne?) et qui inspire au recenseur un non possumus inquiet et sans appel, A. Frigo («Les mytères de Jésus », p. 63-77) analyse le titre sans doute allographe « Le mystère de Jésus » pour questionner la centralité du seul mystère de l'agonie dans la christologie pascalienne, lequel peut bien se soumettre à son tour au mystère de la pénitence, suivant une suggestion d'E. Martineau (p.32-36 et 214-218 des Discours, Paris, 1992) ; enfin, P. Lyraud dans un très bel article, interroge «L'imitatio Christi chez Pascal : l'incorporation comme pratique existentielle ", incorporation à " un Christ qui devient nous " et qui a une portée "existentielle» parce qu'elle décline les trois propositions de la Prière pour demander à Dieu le bon usage des maladies (Fuvres complètes IV 1008) : " pour vous, avec vous, en vous » - ce qui revient, selon le commentateur, à : « donation, conformation, assimilation » (p. 91).

3 Une seconde séquence prend en compte la figure du Christ comme médiateur («Un médiateur: Jésus-Christ, véritable Dieu des hommes»). A. Cousson examine exhaustivement la figure du Christ chez la mère Agnès : au sein d'un « christocentrisme eucharistique » (p. 113, expression empruntée à Ph. Sellier), le Christ apparaît comme une figure consolatrice, toujours morale («Figures du Christ chez la mère Agnès Arnauld », p. 95-115) ; Guy Basset souligne la centralité de la prière et de l'Eucharistie chez le médecin Jean Hamon, à partir de sa Relation de plusieurs circonstances de la vie de Monsieur Hamon faite par lui-même sur le modèle des Confessions de saint Augustin («Les franges de la robe de Jésus-Christ » selon Jean-Hamon, p. 117-126). L'article d'H. Michon touche un point fondamental en posant un diagnostic juste : à l'âge classique, la figure du Christ médiateur se trouve prise en tenaille entre la théologie réformée qui la confisque, et les libertins érudits qui la contestent, double tendance à laquelle la théologie de Port-Royal doit répondre, ce qu'elle fait par la voix d'Arnauld contre La Mothe Le Vayer et par celle de Pascal («Le Christ médiateur: La Mothe Le Vayer, Arnauld, Pascal », p. 127-142). L'apport de Tony Gheeraert est original : examinant le Poème sur la vie de Jésus Christ d'Arnauld d'Andilly (1636), version remaniée de ses Stances pour Jésus-Christ (1628), il montre la force héroïque et épique dont Arnauld d'Andilly dote le Christ, contrastant par là avec l'image que les auteurs de Port-Royal, dont D'Andilly lui-même, donnent et conservent du Christ (p. 143-160).

4 La troisième partie s'intéresse au rapport entre "Christologie et salut ». Laurent Thirouin («Entre morale et mystère : le Christ de Pierre Nicole », p. 163-187) montre que le Christ pour Nicole n'est pas lié au seul souci moral et qu'il n'y a pas lieu de rationaliser le mystère, puisque le Christ reste pour lui « un modèle, une énigme et une lumière » (p. 186) : la présence de Jésus-Christ chez Nicole «manifeste une tension entre deux pôles. La tentation est permanente chez Nicole de donner à sa foi une expression morale. Mais cette tentation est combattue par une authentique conscience de ce qui, dans la personne du Christ, excède la rationalisation, échappe à la parénèse » (p. 166). La contribution technique et précise de Simon Icard («Christologie et doctrine de la grâce à Port-Royal », p. 204) montre, par l'étude des positions de Jansénius, SaintCyran, Pascal et Arnauld, ce que les controverses modernes sur la grâce doivent à un déficit christologique et comme le système janséniste des "causes concourantes » est en tension avec la tradition christologique issue du concile de Chalcédoine. Enfin, $\mathrm{Ph}$. Luez s'intéresse à « Philippe de Champaigne et la figure du Christ : sources, fonctions et enjeux» (p. 205-214) : l'analyse des deux versions du Bon pasteur permet de montrer comment Philippe de Champaigne s'approprie des représentations jusqu'alors absentes dans la peinture catholique mais omniprésentes dans le monde luthérien. 
5 La quatrième partie contribue à nuancer certains portraits de figures célèbres : «Mystères et miracles : de la résurrection à la piété chrétienne ». Fort intéressante est la contribution de Christian Belin («'Entre le ciel et la terre' : le Christ chez Martin de Barcos ", p. 218-228), parce qu'elle tempère l'image de Barcos sombre et rigoriste : sa correspondance fait au contraire état d'un Christ tout en nuance et en mystère, «parole et silence, un Christ médiateur, crucifié entre ciel et terre, entre visibilité et invisibilité [...] configuré [?] au mystère de la prédestination » (p. 218). La contribution de L. Plazenet (p. 229-256) nuance également la figure d'Angélique de Saint-Jean, par l'intérêt qu'éprouve cette dernière pour le Cantique des Cantiques, donnant lieu à une représentation «flamboyante ", une «mortification joyeuse " (p. 243). De même, dans "La Cène de Philippe de Champaigne» (p. 257-273), C. Gouzi analyse le tableau de Philippe de Champaigne en montrant que le peintre a été inspiré par l'art allemand du $\mathrm{xVI}^{\mathrm{e}}$ siècle, ce qui confère à son œuvre une dimension d'apologétique antiprotestante. On retiendra la leçon de F. Plazenet sur la prudence requise dans l'étude de Port-Royal : faire place aux sensibilités individuelles derrière "l'unanimité de façade", c'est s'arracher à l'historiographie du XvIII ${ }^{\mathrm{e}}$ siècle volontiers simplificatrice.

Numéro riche, dense, dépourvu du caractère disparate et inégal qui caractérise souvent pareils collectifs, ce volume se signale à l'avenir comme une référence sur la question. Notons, après un supplément au colloque portant sur «La poésie du Christ chez Pascal » par H. Bouchard (p. 285-306), une synthèse conclusive de L. Devillairs et deux articles de Varia, deux notices d'In memoriam, le premier consacré à Pierre Gasnault (1928-2016) et l'autre à Michel Le Guern. Ils répondent au texte d'ouverture, hommage par Philippe Sellier à l'immense figure des études pascaliennes que fut Jean Mesnard, également disparu en 2016 - décidément «année noire pour tous ceux qui aiment Pascal et Port-Royal » (p. 13).

\section{AUTEURS}

\section{DAN ARBIB}

École normale supérieure, Paris. 